\author{
perifèria
}

Número 15, diciembre 2011

www.periferia.name

\title{
Sentidos identitarios de clase y nación entre los promesantes de los Bailes Religiosos de Calama (Chile) ${ }^{1}$
}

\author{
Javier Mercado Guerra - Grup de Recerca CIUTADANIES, Institut Català \\ $\mathrm{d}^{\prime}$ Antropologia / Universitat de Barcelona ${ }^{2}$
}

\section{Resumen}

En este artículo se presentan los primeros resultados obtenidos a partir de un estudio histórico y etnográfico sobre las agrupaciones de Bailes Religiosos de la ciudad de Calama (Chile). Desde una perspectiva situada en los estudios de la subalternidad, se sugiere la relevancia que estas agrupaciones religiosas han tenido en los procesos de configuración histórica de las identidades de clase y nacionales en esta zona del norte de Chile.

Palabras clave: Bailes Religiosos, estudios subalternos, identidad de clase, identidad nacional, norte de Chile.

\begin{abstract}
This article presents the first results obtained from a historical and ethnographic research about groups of 'Bailes Religiosos' in the city of Calama (Chile). From a perspective located in the subaltern studies, it suggests the relevance of these religious groups in the processes of historical configuration of class and national identities in this region of northern Chile.
\end{abstract}

Key words: 'Bailes Religiosos', subaltern studies, class identity, national identity, north of Chile.

\footnotetext{
${ }^{1}$ Los trabajos de investigación en terreno y en archivo sobre los cuales se sustenta este artículo, han sido posibles gracias a la Beca de Estadía Corta 2008 otorgada por la Universidad de Chile y al Programa CONICYT Becas Chile. Este artículo se basa en la tesina de máster titulada: "Identidades promesantes: Procesos de construcción identitaria en los Bailes Religiosos de Calama, Chile", presentada en la Universidad Autónoma de Barcelona en julio de 2011. Agradezco a mi directora, Dra. Montserrat Clua, por todo su apoyo durante la elaboración de la tesina.
}

${ }^{2}$ Enviar correspondencia a: jmercado.guerra@gmail.com 


\section{perifèria}

Número 15, diciembre 2011

www.periferia.name

\section{Introducción}

El presente artículo tiene por objetivo presentar parte de los resultados obtenidos a partir de una investigación centrada en un difundido fenómeno religioso desarrollado en el norte de Chile. Concretamente, se abordará el caso de las agrupaciones de Bailes Religiosos de la ciudad de Calama, las que participan cada año en la popular fiesta de la Virgen de Guadalupe en el poblado precordillerano de Ayquina, Provincia de El Loa, Región de Antofagasta, Chile.

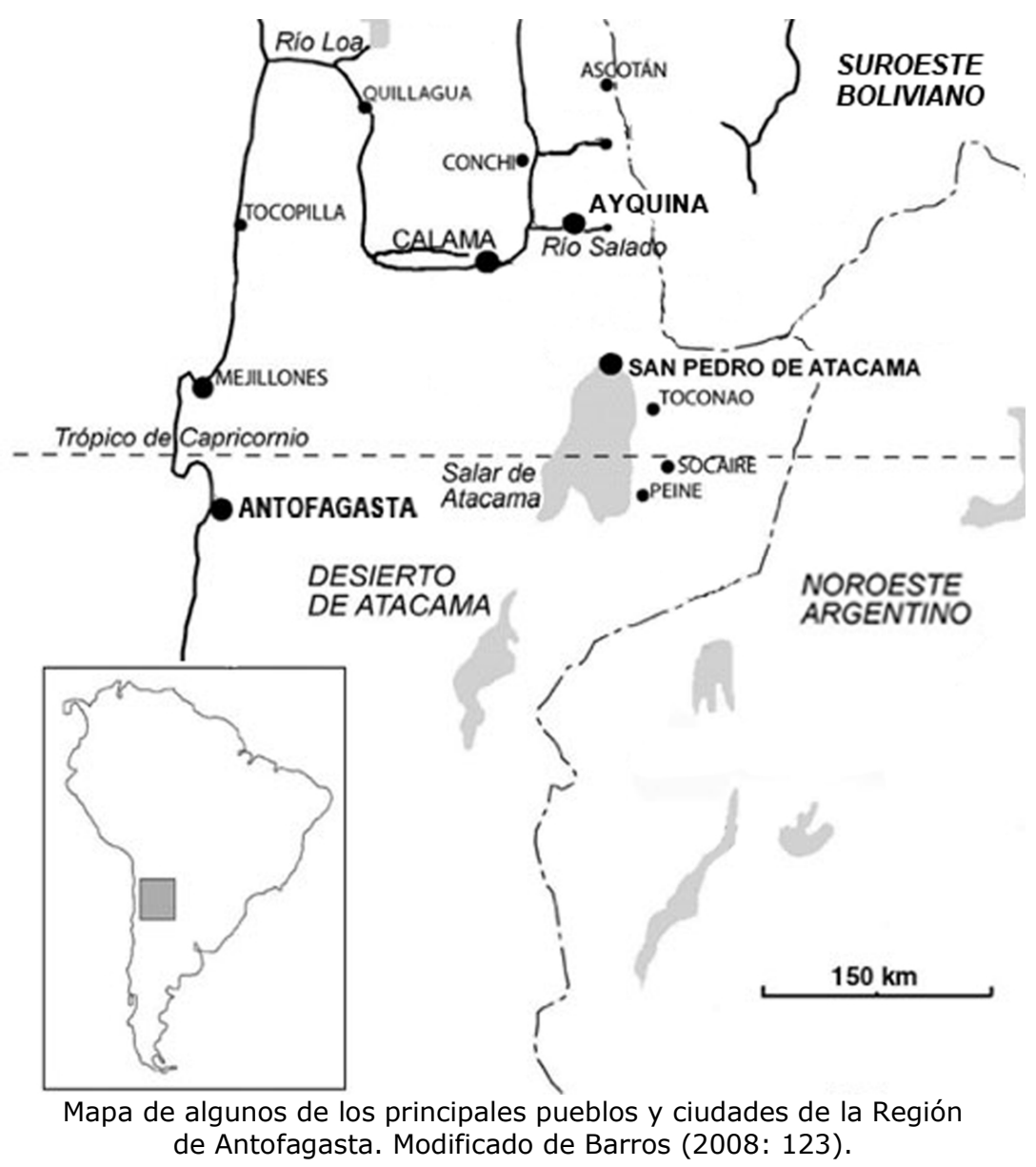

Los Bailes Religiosos constituyen organizaciones de devotos/danzantes -también llamados "promesantes"- que profesan devoción hacia una determinada virgen o 


\section{perifèria}

Número 15, diciembre 2011

www.periferia.name

patrono del santoral católico. Estas organizaciones son denominadas como Bailes Religiosos debido a que la principal actividad que desarrollan sus integrantes -como parte de su demostración de fe, o bien como forma de pago de alguna manda o promesa (de ahí su denominación como "promesantes")- es danzar por turnos durante varios días consecutivos, en el trascurso de la festividad religiosa dedicada a la virgen o santo patrono correspondiente. En otros lugares de los Andes, como Perú y Bolivia, este tipo de agrupaciones son conocidas respectivamente como "cofradías" o "fraternidades folklóricas".

La definición de este "objeto" de estudio tiene sus orígenes, más que en un interés por el fenómeno religioso en sí mismo, en una serie de cuestionamientos relativos a los procesos de configuración histórica de la identidad de clase entre los trabajadores mineros del norte de Chile (Mercado 2005, 2009, 2010). Sustentado inicialmente en las propuestas de E. P. Thompson (1963, 2000 [1976]), donde se destaca la importancia de la tradición "folklórica" de los trabajadores y se reflexiona sobre cómo estos elementos pueden incidir en la conformación de sus identidades de clase, comencé a cuestionarme respecto a cómo determinados elementos culturales -como son la conocida devoción mariana profesada por la mayoría de los obreros mineros del norte de Chile a través de los Bailes Religiosos-, pueden incidir de manera gravitante en la emergencia de las identidades de clase.

Esta perspectiva de análisis, que pretende relacionar una determinada práctica religiosa o ritual con la emergencia de los procesos históricos de configuración identitaria entre sectores obreros, aborda un tema similar al desarrollado por una serie de etnografías sobre los trabajadores mineros en los Andes. La problemática central de dichas investigaciones (Nash 1979; Taussig 1980 [2010]; Platt 1983; Salazar-Soler 1987, 2002; Absi 2005) ha sido, precisamente, el estudio de las complejidades identitarias surgidas a partir de los procesos de proletarización en contextos donde la mano de obra proviene básicamente de sectores rurales y/o indígenas. Sin embargo, para el caso del norte de Chile, existe claramente una carencia de investigaciones orientadas en este sentido; es decir, centradas en los aspectos socioculturales de la población migrante que comenzó a ser atraída hacia el Desierto de Atacama, en el norte de Chile, durante los sucesivos ciclos de auge 


\section{perifèria}

Número 15, diciembre 2011

www.periferia.name

minero desarrollados entre fines del siglo XIX y durante gran parte del XX.

A partir de este amplio marco de análisis, en esta investigación se ha pretendido indagar en los procesos de conformación de las identidades socioculturales de los promesantes de los Bailes Religiosos en la ciudad de Calama, a partir de las incidencias que han tenido históricamente y tienen en la actualidad las experiencias festivo-religiosas y las expresividades coreográficas implicadas en la práctica ritual. Si bien el foco principal del análisis se ha centrado en la configuración de las identidades de clase, a través del propio desarrollo de la investigación se ha percibido la importancia que también han tenido los Bailes Religiosos en la configuración de las identidades nacionales en una zona de frontera como lo es el norte de Chile.

De esta forma, la hipótesis central que he ido definiendo es que los Bailes Religiosos, por medio de la práctica ritual y la expresividad coreográfica, han llegado a constituirse en mecanismos de configuración de las identidades colectivas de clase y nación, a través de los cuales se expresan usualmente anclajes de "alteridad" o "diferencia". Sin embargo, existirían algunas ocasiones donde el sentido de alteridad implicado en estas representaciones se modifica y los promesantes pasarían a adoptar determinadas danzas rituales como vehículo de expresión de su propia "identidad". Para comprender este sutil juego de diferenciaciones entre los sentidos de "alteridad" e "identidad" desarrollados por los promesantes de los Bailes Religiosos, resulta fundamental atender a las sugerencias de Spivak (2009 [1993]) respecto a la diferencia entre una "re-presentación" (en un sentido artístico o filosófico) y una "representación" (en un sentido político).

De esta forma, en el presente artículo se exponen los primeros resultados de investigación avanzados con respecto a tres puntos en concretos. En una primera parte, presentaré algunos de los principales lineamientos teóricos adoptados para la interpretación del fenómeno de los Bailes Religiosos en el norte de Chile. En la segunda parte, se presentará una síntesis de los primeros resultados e hipótesis centrales sobre el desarrollo histórico de la fiesta de Ayquina y los Bailes Religiosos. $Y$ en una tercera parte, se presentará una breve síntesis de las principales conclusiones obtenidas a partir del análisis etnográfico realizado en torno al 


\section{perifèria}

Número 15, diciembre 2011

www.periferia.name

fenómeno de los Bailes Religiosos de Calama y sus participaciones en las festividades anuales de la Virgen de Ayquina.

\section{Identidad y ritual. Una definición teórica para el estudio de los Bailes Religiosos}

La definición de una perspectiva teórica con el fin de abordar el fenómeno de los Bailes Religiosos, ha implicado un largo recorrido a través del cual se han podido llegar a definir dos problemáticas centrales: el problema de la configuración de las identidades colectivas, específicamente de clase y nacionales; y otra perspectiva de análisis situada en los fenómenos folklórico-rituales, teniendo siempre en consideración la importancia que estos pueden llegar a adquirir dentro de los procesos de configuración identitaria.

\subsection{Identidad de clase y nacional}

En una primera parte de la discusión teórica, se ha intentado indagar en las principales líneas de debate que se han desarrollado dentro del campo de las ciencias sociales en relación con los estudios sobre trabajadores mineros; destacando fundamentalmente las tesis sociológicas sobre el surgimiento de la clase obrera en América Latina y más específicamente en las zonas mineras andinas de Bolivia, Perú y el norte de Chile.

Un aspecto interesante y muy notorio dentro de las investigaciones historiográficas y sociales referidas a la minería, es que éstas suelen enfocarse en las consecuencias propias de la implantación y desarrollo de un modo de producción capitalista, como son los procesos de industrialización o emergencia de una clase obrera organizada. De esta forma, se constata que los estudios etnográficos sobre minería son más bien escasos y recientes, más aun considerando que la antropología ha sido una disciplina que tradicionalmente ha privilegiado el estudio de sociedades "precapitalistas" (García, et al. 2002).

Circunscribiendo la problemática al contexto latinoamericano y centrado en la consideración de los grupos mineros en tanto sectores sociales situados en lo que 


\section{perifèria}

Número 15, diciembre 2011

www.periferia.name

se comprende tradicionalmente como las clases trabajadoras o proletarias, se podría establecer que los modelos de interpretación a nivel general referidos a los comportamientos e identidades de los sectores excluidos o menos privilegiados en los países latinoamericanos (ya sean sectores de la clase obrera, sectores marginales, sectores populares, poblaciones indígenas, etc.) consisten básicamente en tres grandes tesis asentadas en la tradición sociológica:

1) Un tipo de análisis que sostiene la necesidad de modernizarse y superar las formas de vida tradicional para alcanzar el desarrollo económico, en lo que vendría a ser el discurso clásico desde una óptica "desarrollista" latinoamericana centrada en los postulados "weberianos" (Weber 1970 [1946]: 56-57).

2) Un análisis igualmente centrado en la necesidad de alcanzar el desarrollo, pero complementado con la idea de la "lucha de clases" al interior de cada entidad nacional, en lo que vendría a ser el postulado de la "teoría de la dependencia" y otras posturas de tipo marxista (Cardoso, Faletto 1971 [1969]).

3) $Y$ un tercer enfoque que rescata la importancia de los elementos culturales tradicionales para el desarrollo de procesos autónomos de la lucha obrera y/o popular, en lo que sería una especie de discurso "contramoderno" que también ha tomado elementos de la crítica marxista (Nash 1979; Taussig 2010; Platt 1983) e incluso de la "teología de la liberación" (Laan 1993; Van Kessel 1992).

Desde esta perspectiva, y en lo que a este trabajo de investigación se refiere, se ha considerado importante realizar una aproximación en profundidad hacia las reconceptualizaciones de las categorías de análisis obradas al interior de la tradición marxista. Siguiendo la línea de los estudios etnográficos sobre trabajadores mineros en los Andes, e intentando tomar distancia de las teorías sociológicas desarrollistas, resulta fundamental ahondar en otras consideraciones teóricas más actuales, como son los estudios postcoloniales y el postestructuralismo, ya que éstos han constituido, precisamente, algunos de los intentos teóricos más relevantes orientados a superar los antiguos enfoques sociológicos estructuralistas.

Es así como los estudios postcoloniales nos plantean consideraciones altamente relevantes en lo que al análisis de las identidades socioculturales se refiere. 


\section{perifèria}

Número 15, diciembre 2011

www.periferia.name

Particularmente, resulta interesante constatar cómo las teorías postcoloniales reelaboran o "de-construyen" la idea de identidad de clase, asumiendo en el concepto gramsciano de subalternidad una propuesta de interpretación más amplia, específicamente al considerar que las experiencias de subordinación pueden constituirse también a partir de situaciones de dominación sustentadas, por ejemplo, en categorizaciones étnicas, de raza, de género o de nación (Hall 1996), aspecto altamente relevante sobre todo en países que han tenido un pasado $\mathrm{y} / \mathrm{o}$ tienen un presente determinado por los procesos de dominación colonial. Se complejiza de esta forma el panorama de las identidades $y$, en términos más concretos, se produce un profundo cuestionamiento de las nociones clásicas de sujeto social que tanta relevancia han tenido dentro de las ciencias sociales. Siguiendo este tipo de propuestas, se ha considerado pertinente redirigir el punto de reflexión pasando desde lo que podría ser un análisis centrado en un sujeto social en concreto -como podría ser la "clase obrera" o un "sujeto minero"- hacia determinadas prácticas culturales y observar cómo, en torno a ellas, se van encarnando o materializando los más diversos discursos identitarios.

En síntesis, ambas críticas sobre la idea de identidad de clase podrían resumirse, en primer lugar, como una crítica postcolonial respecto a la multiplicidad de factores que operan en una situación de dominación y, en segundo lugar, como una crítica postestructuralista sobre la idea de un sujeto social homogéneo. Para asir estas críticas bajo una conceptualización teórica específica, se ha tomado la propuesta de Kathy Davis (2008) a través de la cual se destaca la importancia de la noción de "interseccionalidad" surgida al interior de los estudios feministas. Según Davis, este concepto constituye uno de los mayores aportes del feminismo, puesto que sería un concepto:

idealmente adecuado para la tarea de explorar cómo las categorías de raza, clase y género se entrecruzan y constituyen mutuamente, dando centralidad a preguntas sobre cómo la raza es "generizada" y cómo el género es "racializado", y cómo ambos están vinculados a las continuidades y transformación de la clase social. (Davis 2008: 71)

Para el caso de los Bailes Religiosos en el norte de Chile, sería imposible 


\section{perifèria}

Número 15, diciembre 2011

www.periferia.name

comprender las categorizaciones de clase social construidas en torno a este fenómeno, sin abarcar otros ámbitos discursivos que se entrecruzan con estas, como por ejemplo, las categorizaciones de etnia/nación. En este mismo sentido, se requería de un emplazamiento que abogue por una mirada sobre los discursos e ideologías que envuelven y dan vida a lo que usualmente entendemos, en este caso, como manifestaciones folklórico-religiosas. De esta forma, podemos ir estableciendo una aproximación más clara hacia los mecanismos normativos que cargan de sentido y significación a determinadas prácticas culturales, las que además reclaman para sí un papel representativo -es decir, de identidad- sobre determinados miembros de una clase, una región, una etnia y/o una nación.

\subsection{Folklore y representación}

El proceso de reflexión seguido con el objetivo de definir una perspectiva de análisis sobre los Bailes Religiosos, ha derivado en la necesidad de una aproximación teórico-conceptual sobre lo que se consideran como prácticas folklóricas y rituales. La línea de discusión seguida sobre este punto sostiene, en primer lugar, una reflexión respecto a las vinculaciones entre folklore y antropología, donde resultan clave los desarrollos teóricos y metodológicos realizados desde la antropología italiana de tradición gramsciana. Ernesto de Martino, uno de los principales expositores de esta tradición de estudios, es quien de alguna manera abre las puertas de la antropología a las reflexiones de Antonio Gramsci sobre el folklore (2004 [1934]). En un primer momento, De Martino establece la necesidad de realizar un esfuerzo analítico por comprender a las clases subalternas como tal, incluso sobre la situación religiosa del pueblo y el rol hegemónico jugado por la Iglesia Católica. Se trata, sin duda, de una reflexión marxista bastante heterodoxa donde se comprende que la experiencia de la clase obrera tiene una gran variación cultural. De esta forma, De Martino reclama:

la necesidad de dialogar continuamente con la cultura de la tradición, con las formas nacionales asumidas por esta cultura, con la historia nacional en su conjunto. De ello se sigue que el marxista, el ideólogo militante de la clase obrera, debe dominar la cultura de su país, ya sea en la forma más elevada, 


\section{perifèria}

Número 15, diciembre 2011

www.periferia.name

más refinada, o bien en la forma popular religiosa o supersticiosa: solo así su marxismo será conciencia viva, históricamente arraigada. (De Martino 2008: 75)

Es así como De Martino plantea el concepto de "folklore progresivo", con el fin de dejar establecida la ambigüedad o el sentido intrínsecamente contradictorio que posee el folklore, ya que éste no sólo se trataría de una cultura de la tradición, sino que también puede llegar a constituirse en un "folclore progresivo, que es una propuesta consciente del pueblo contra la propia condición socialmente subalterna, o que comenta y expresa, en términos culturales, las luchas por emanciparse" (De Martino 2008: 107). Siguiendo esta perspectiva marxista heterodoxa de relación entre folklore y antropología, se hace necesario revisar el concepto - tan utilizado como poco definido - de subalternidad y su relación con el denominado dilema de la representación; dada la importancia que esta perspectiva de análisis tiene a la hora de comprender las expresiones consideradas como folklore-religioso dentro de las cuales podemos enmarcar al fenómeno de los Bailes Religiosos.

La diferenciación sobre los sentidos del término de representación, nos aporta una serie de elementos para comprender la relación que puede existir entre una manifestación folklórica y la propia idea de subalternidad. Convengamos en señalar que el argumento central del "enmarañado" pero trascendental texto de Spivak (2009) relativo a la subalternidad - y que tomaré como guía para adentrarme en este debate -, es el de discutir los planteamientos de dos "intelectuales radicales hegemónicos": Gilles Deleuze y Michael Foucault. Spivak sostiene que la conocida crítica que estos intelectuales desarrollaron sobre el sujeto soberano, "inauguró realmente un [nuevo] Sujeto" (Spivak 2009: 43); ya que, sin darse cuenta, al establecer que los sujetos oprimidos pueden hablar por sí mismos y que no requieren de una representación, estos intelectuales están reproduciendo la idea de una ideología entendida como una "falsa conciencia", la que fuera puesta en duda a partir las reflexiones de Louis Althusser (2003).

Sin embargo, el elemento más relevante a considerar en el argumento de Spivak es la crítica realizada a Gilles Deleuze por no haber estado lo suficientemente atento al significante "representación"; representación quiere decir tanto "hablar por" 


\section{perifèria}

Número 15, diciembre 2011

www.periferia.name

alguien, tal como sucede en el campo político, como "volver a presentar algo", tal como sucede en el campo del arte o la filosofía:

Atendamos -dice Spivak- al juego de vertreten ('representar' en el primer sentido) y darstellen ('re-presentar' en el segundo sentido) en un famoso pasaje de El dieciocho brumario de Luis Bonaparte donde Marx alude a la 'clase' como concepto descriptivo y transformador de un modo más complejo que lo que permitía la distinción establecida por Althusser entre instinto de clase y posición de clase [...]. En mi opinión, Marx no intenta crear un sujeto compacto en el que coincidan el deseo y el interés. La conciencia de clase no persigue ese objetivo. Tanto en el área económica (capitalista) como en la política (el agente del mundo histórico), Marx se ve obligado a construir modelos de sujeto dividido y dislocado cuyas partes no son continuas o coherentes entre sí. (Spivak 2009: 57)

En este sentido, Spivak comienza a perfilar su conclusión: que el subalterno "no puede hablar" y que, por lo tanto, tiene que ser necesariamente representado. Esta diferenciación entre los sentidos que tiene la noción de representación, me parece que constituye un elemento clave a tener en cuenta en el momento de adentrarnos en los significados identitarios que tienen las prácticas rituales y las expresividades coreográficas, desarrolladas por los promesantes de los Bailes Religiosos en el norte de Chile. Es así como a través de esta propuesta de definición teórica del problema, se incorpora una perspectiva metodológica que transita entre un análisis diacrónico y uno sincrónico, puesto que es a través del proceso histórico y de sus anclajes en el presente etnográfico donde podemos arribar a un sentido más global de interpretación del fenómeno investigado. De esta forma, se presentarán en primer lugar las principales conclusiones e hipótesis formuladas sobre el desarrollo histórico de la fiesta de Ayquina y el fenómeno de los Bailes Religiosos, para luego continuar con las conclusiones obtenidas a partir de las miradas etnográficas en torno a este mismo fenómeno. 


\section{perifèria}

Número 15, diciembre 2011

www.periferia.name

\section{Una mirada histórica sobre la fiesta de Ayquina y los Bailes Religiosos}

El pequeño pueblo de Ayquina, lugar donde se desarrolla la festividad patronal investigada, tiene sus orígenes en los procesos coloniales de reducción indígena en los Andes (Martínez 1985; Castro y Martínez 1996). El mito de origen de la fiesta de la Virgen de Guadalupe se encuentra directamente relacionado con la creación del pueblo, ya que "los habitantes de Ayquina narran que antiguamente no vivían en ese lugar y que ahora lo hacen por un acontecimiento divino" como lo fue la aparición de la Virgen (Castro y Martínez 1996: 77). Es importante señalar que esta tradición oral sobre el "mito de origen" de la fiesta y del pueblo, mantenida por los propios habitantes de Ayquina, también es recreada por los fieles devotos de la Virgen de Guadalupe que vienen de otros lugares cercanos, principalmente de la vecina ciudad minera de Calama. Esta historia de la fiesta y del pueblo de Ayquina reconstruida a través de documentos históricos y de relatos orales - configura una diacronía histórica que tiene su punto de inflexión más relevante en las primeras décadas del siglo XX. Por aquellos años, junto con el auge de la explotación minera y la consecuente inmigración de poblaciones provenientes desde distintos puntos de Chile y del área andina circundante, se desarrolla también una suerte de proceso de "re-fundación" de algunas pequeñas festividades patronales locales que, en este contexto, devienen en grandes festividades religiosas de orden regional (Núñez 2004; González 2006).

Es curioso evidenciar que el periodo que va entre fines del siglo XIX y comienzos del $X X$, reconocido dentro de la historiografía chilena y nortina como el periodo de auge de los movimientos obreros vinculados al desarrollo minero, constituye también el momento de masificación de este tipo de expresiones religiosas. De hecho, a mi parecer este fenómeno cuestiona la idea de la secularización, ya que, en el caso del norte de Chile, a medida que los procesos de industrialización y proletarización minera se van profundizando, más creyentes se van sumando a las dinámicas religiosas locales.

A través del trabajo de reconstrucción histórica realizado sobre el desarrollo de la 


\section{perifèria}

Número 15, diciembre 2011

www.periferia.name

fiesta de Ayquina y sus Bailes Religiosos, he logrado percibir la existencia de dos etapas fundamentales.

Una primera etapa sería la "re-fundación" de la fiesta propiamente tal, ocurrida entre los años 1930 y 1960 aproximadamente, y donde se desarrolla un claro proceso de "invención de tradiciones" (Hobsbawm 2002) en el que se encuentran involucrados mayoritariamente los sectores obreros del ex-campamento minero de Chuquicamata, vecino a la ciudad de Calama. Este proceso de invención de tradiciones - que corre en paralelo con los primeros procesos de sindicalización formal y politización entre los trabajadores mineros de Chuquicamata - se expresó tanto en la creciente devoción manifestada hacia la Virgen de Ayquina, así como también en la activa participación dentro de las organizaciones de Bailes Religiosos. Considerando que los grupos involucrados en esta etapa temprana de refundación de la fiesta de Ayquina, en su gran mayoría constituían grupos migrantes internos provenientes del Norte Chico y zona Central de Chile, así como también de sectores andinos de la zona y de Bolivia principalmente, se podría sostener la hipótesis de que la participación en la fiesta religiosa constituyó un cierto "paliativo social" que vino a suplir el desarraigo implicado en el proceso de migrar e instalarse en un lugar inhóspito, como el Desierto de Atacama, donde el contexto social está dominado por las exigentes condiciones laborales. Sin lugar a duda, hay mucho de aquello en este proceso de invención de tradiciones. Sin embargo, creo que también es importante destacar el papel de estas expresiones rituales no sólo como lugar de "refugio" de las nuevas masas proletarias desarraigadas, sino también como instancias de agencia donde se van configurando las identidades colectivas. Incluso podríamos pensar - tal como plantea June Nash (1979) respecto a los mineros bolivianos - que estas instancias rituales constituyen también mecanismos a través de los cuales se configuran o refuerzan las propias identidades de clase que emergían por aquella época entre los trabajadores mineros.

La segunda etapa que he identificado estaría marcada por una mayor expansión de la fiesta de Ayquina y una creciente influencia "andina" en la fundación de nuevos Bailes Religiosos; etapa que se iniciaría en la década de los años sesenta y que continuaría prácticamente hasta la actualidad. Durante esta etapa, los Bailes 


\section{perifèria}

Número 15, diciembre 2011

www.periferia.name

Religiosos comenzaron a tener como punto de referencia un contexto cultural andino general, a diferencia de la etapa anterior donde las representaciones implicadas en las danzas eran mucho más diversas (podían representarse a través de la danza a indios piel roja, gauchos, piratas, toreros, etc.). En este proceso de cambio cualitativo pueden haber jugado a favor una serie de factores, como por ejemplo la expansión de los medios de comunicación masivos. Sin embargo, me parece que estamos ante un fenómeno mucho más complejo y que tiene que ver, precisamente, con las singulares formas de construcción identitarias que comienzan a desarrollar los mismos promesantes de la Virgen de Ayquina.

Un buen punto de partida para proponer una explicación a este fenómeno de integración más acentuada de danzas de origen andino a la fiesta de Ayquina, es considerar el dilema de la representación y la subalternidad (Spivak 2009), al que me he referido en la primera parte de este artículo. Me parece claro que, más allá de la búsqueda de canales de expresión de fe desarrollados en un comienzo por las familias mineras de Calama y Chuquicamata, la fiesta de Ayquina y los Bailes Religiosos vinieron a constituirse en vehículos de expresión de las identidades a través de danzas que expresan anclajes de "alteridad" o "diferencia". Estos sentidos de alteridad marcarían una diferencia en relación con la propia identidad nacional que se supone deberían tener los promesantes. En este sentido, al integrar e interpretar danzas de origen andino - especialmente vinculadas a la identidad nacional boliviana - se permitiría establecer un marcador simbólico de diferencia en el contexto de la identidad nacional hegemónica emanada desde el centro de Chile. De igual forma, la participación en los Bailes Religiosos comienza a constituirse en un marcador identitario de clase para los promesantes, quienes logran establecer una diferencia entre su propio modo de expresión de la fe católica en relación al que desarrollan otros grupos sociales más acomodados, quienes no suelen participar de las manifestaciones de devoción típicamente promesantes y suelen más bien apegarse a las formas del culto oficial establecido por la Iglesia Católica.

Considerando estos elementos, podemos comprender cómo es que en un comienzo los promesantes prefieren tomar como puntos de referencia en sus danzas a grupos sociales ajenos al contexto local como toreros, gauchos, pieles rojas, etc. Sin 


\section{perifèria}

Número 15, diciembre 2011

www.periferia.name

embargo, cuando se asume una re-presentación (en el sentido artístico o filosófico aludido por Spivak) de grupos sociales o étnicos más cercanos, como son los de referencia andina, esta idea de "alteridad" se viene a modificar en al menos dos sentidos: o se pasa a una identificación más acentuada con lo re-presentado, o se mantiene como una marca de alteridad donde la danza se establece como una forma de representación (ahora en sentido político) de los grupos sociales o étnicos aludidos.

Si tomamos en consideración la propuesta que ha venido desarrollado Thomas Abercrombie $(1992,2003,2006)$ sobre las implicaciones políticas que tienen las representaciones folklórico-coreográficas - que aluden a "lo indígena andino" por parte de los grupos de élites o clases medias urbanas en Bolivia -, en este caso estaríamos también ante una depurada técnica semiótica que les permitiría a los grupos mineros de Chuquicamata y Calama pasar a "ser" sus propios indios y al mismo tiempo trascenderlos a través de dramas celebratorios que invocan el viejo tópico cristiano del teatro misionero. Esto que Thomas Abercrombie ha denominado como el "dilema postcolonial" en Bolivia - y que también he venido desarrollando (Mercado 2011) -, adquiere algunas características muy singulares para el caso del norte de Chile, ya que como "telón de fondo" tenemos los conflictivos procesos de construcción de las identidades nacionales en estos territorios de frontera. Así, mediante esta incorporación sistemática de elementos referenciales andinos, se iría configurado un entramado de significados identitarios que en este caso, más que señalar elementos de sociabilidad e identidad de clase, comienzan a situarse como elementos referenciales de una incipiente identidad regional que tensiona la difundida idea de una identidad nacional chilena homogénea emanada desde el centro del país.

Es así como los promesantes de la Virgen de Ayquina comenzarían a asumir, a partir de los años sesenta, una "representación" (política) sobre los grupos étnicos andinos, expresando así una clara tensión interna entre identidad y alteridad. En un sentido de identidad, comprendido como una vinculación relativamente consciente hacia el contexto andino, estableciendo por contrapartida un distanciamiento o diferenciación identitaria con la cultura chilena hegemónica. $Y$ en un sentido de 


\section{perifèria}

Número 15, diciembre 2011

www.periferia.name

alteridad, si comprendemos - tal como establece Abercrombie (1992) - que este tipo de danzas que aluden a lo "indígena andino" forman parte de una macronarrativa de la conversión donde los sectores altos y medios urbanos de la sociedad pasan a "representar" al indio, dejándolo por tanto sin capacidad de hacer escuchar su "propia voz" dentro de la escena política nacional.

De todas formas, esta hipótesis de interpretación que he venido elaborando a partir del trabajo de indagación histórica sobre la fiesta de Ayquina y los Bailes Religiosos, me parece que debería ser contrastada necesariamente con los datos etnográficos recabados, sobre todo considerando que los elementos referenciales andinos a los que me refiero continúan estando muy presentes en la actualidad.

\section{Una mirada etnográfica sobre los Bailes Religiosos de Calama}

Luego de los trabajos etnográficos desarrollados en 2008 y 2010 durante las fiestas de Ayquina, he podido constatar, en primer lugar, que la experiencia de los promesantes de los Bailes Religiosos de Calama sigue siendo relevante como una instancia de configuración o reafirmación de las identidades de clase. Un buen punto de partida, en este sentido, es observar los conflictos o fricciones internas entre los mismos promesantes de los Bailes Religiosos. A través de ellos, se suelen explicitar o poner en relación las propias diferenciaciones de clase que se estructuran en la vida social calameña. Las dinámicas de interacción y tensión entre las clases sociales se expresan al interior de cada Baile Religioso, e incluso también pueden llegar a constituirse en espacios donde se estructuran dichas identidades.

Sin embargo, además de esta dinámica de interacción entre individuos dentro de los Bailes Religiosos, también he notado la existencia de una especie de discurso de clase configurado a partir de la interacción entre los propios Bailes en cuanto organizaciones. Resulta fundamental, en este sentido, destacar la diferenciación que la mayoría de los promesantes establece entre "Bailes chicos" y "Bailes grandes". Esta diferenciación construida por los propios promesantes - que casi alude a una idea de "ricos y pobres" - suele establecerse, en principio, para describir las dimensiones de cada Baile Religioso según su número de integrantes. 


\section{perifèria}

Número 15, diciembre 2011

www.periferia.name

Sin embargo, el sentido de esta diferenciación entre Bailes chicos y Baile grandes no se limita a sus dimensiones o a la cantidad de integrantes que cada agrupación posee, sino que también está revestida de una serie de consideraciones éticas que se refieren, usualmente, a la poca pertinencia del lujo (gestos arrogantes y vestimentas vistosas) que suelen demostrar los promesantes que integran algún Baile considerado como grande, en contraste con los valores positivos de humildad y sencillez que representarían los integrantes de los Bailes considerados como chicos.

A partir de estas observaciones, he llegado a percibir la existencia de toda una ética promesante que muchos de ellos se esfuerzan por mantener y que pareciera estar relacionada directamente con algunas consideraciones de clase. Esta ética parece apelar a una serie de valores vinculados a la sobriedad y el buen comportamiento que cada promesante debe mantener durante la celebración de la fiesta de la Virgen de Ayquina. Por ejemplo, muchos promesantes que son asiduos bebedores de alcohol se esfuerzan por mantener una especie de actitud ascética, que en este caso implica la abstención a consumir bebidas alcohólicas durante el transcurso de la fiesta. Un promesante me dijo alguna vez, criticando a un músico de una de las bandas que acompañan a los Bailes Religiosos y que fue encontrado borracho, que "pa' que vai a tomar [beber alcohol] en la fiesta, si tenís trescientos y tantos días al año pa' tomar". Este ejemplo ilustra bien esta actitud de recogimiento y respeto que muchos promesantes se esfuerzan por mantener.

De igual manera, esta especie de ética promesante incide en la configuración de una serie de críticas que algunos de ellos dirigen hacia quienes consideran que participan en un determinado Baile Religioso por razones de prestigio y apariencias. Estas críticas suelen ser vertidas por los promesantes que participan, justamente, en los Bailes chicos, quienes consideran que muchos de los que participan en Bailes grandes han perdido el sentido básico de devoción y humildad que deben demostrar durante la celebración religiosa. Sin embargo, esta especie de resquemor existente hacia el creciente lujo o "lucimiento" - como suelen decir los promesantes - es un fenómeno que no debería extrañarnos dentro del contexto de las festividades religiosas andinas. Por ejemplo, en las festividades patronales 


\section{perifèria}

Número 15, diciembre 2011

www.periferia.name

urbanas de Bolivia, muchas de las cuales son situadas como puntos de referencia por los mismos promesantes calameños, el lujo constituye un elemento clave como distintivo social, por lo que muchos investigadores han llegado a percibir a las Fraternidades Folklóricas (nombre que reciben en Bolivia las agrupaciones de danzantes que realizan actividades similares a los Bailes Religiosos del norte de Chile) como instancias sociales donde se configuran las relaciones de poder y prestigio al interior de los grupos urbanos.

A partir de esta distinción entre lujo y sencillez, podemos pasar a comprender el otro eje central que he percibido en la construcción identitaria de los promesantes hoy en día: la pertenencia nacional. Un primer elemento a tener en cuenta para comprender la distinción que los propios promesantes establecen entre Bailes "chilenos" y "bolivianos", es el conflictivo pasado histórico que permea esta zona fronteriza andina entre Chile y Bolivia ${ }^{3}$. Otro elemento a considerar es que, justamente, los Bailes "chilenos" suelen coincidir con los Bailes "chicos" y que los Bailes "bolivianos" suelen coincidir con los Bailes "grandes".

En este sentido, un elemento muy notorio es que la gran mayoría de los promesantes suelen tener bastante clara la procedencia de la danza que interpretan (sea esta procedencia factual o construida simbólicamente); el caso es que este límite configura otro eje fundamental a partir del cual los promesantes otorgan sentido a sus identidades colectivas. Por ejemplo, Carlos, del Baile Tinkus de Calama (considerado como un Baile "grande y boliviano"), sostiene de forma explícita esta distinción nacional entre Bailes chilenos y bolivianos: "el Baile Piratas de Cristo Rey, ese es chileno. Y después de ese Baile me fui a un Awatiri, que ese

\footnotetext{
${ }^{3}$ La actual Región de Antofagasta, donde se encuentra situada la ciudad de Calama, formó parte del territorio boliviano hasta 1883, fecha tras la cual el Estado chileno anexa a perpetuidad las regiones de Antofagasta y Tarapacá en desmedro de los estados de Bolivia y Perú, respectivamente. Esto ocurre luego de que el ejecito chileno logre vencer en la denominada Guerra del Pacífico o del Salitre (18791883). Este conflicto bélico que enfrentó a Chile con Bolivia y Perú, tensiona hasta el día de hoy las relaciones diplomáticas entre dichos países, además de constituirse en un importante elemento simbólico dentro de la configuración de las identidades nacionales.
} 


\section{perifèria}

Número 15, diciembre 2011

www.periferia.name

es boliviano" ${ }^{4}$. Podría mencionar muchos más ejemplos de este tipo, pero quisiera más bien adentrarme en los significados más profundos que tiene, para determinados promesantes, el hecho de participar actualmente en un Baile Religioso que interpreta una danza considerada socialmente como boliviana. Luis, también del Baile Tinkus, me comenta sobre la creación del Baile:

Los que partimos de alguna manera como líderes, veníamos desde chicos con el conocimiento del folklore boliviano, digamos bastante amplio. Habíamos tenido la experiencia de ir a Bolivia, teníamos los contactos por el tema de los trajes, es decir, no nos estábamos metiendo a algo que no conociéramos.

Teníamos plena claridad de la vestimenta, etc. ${ }^{5}$

El hecho clave radica en que este conocimiento del "folklore boliviano", se debe a que muchos de ellos son descendientes de ciudadanos bolivianos oriundos de la zona cuando ésta todavía estaba en manos de Bolivia, o bien son descendientes hijos o nietos - de migrantes bolivianos. Este es el caso del propio Luis (nieto de boliviana) y Carlos (hijo de padre y madre boliviana).

En este sentido, debemos comprender que los promesantes mantienen una clara distinción en torno a los significados atribuidos a las danzas que interpretan. Específicamente, quienes interpretan danzas que proceden del "folklore boliviano", parecieran desarrollar un nivel más alto de implicación con lo "re-presentado" a través de la danza. Si siguiéramos la distinción sobre los significados de la "representación", podríamos decir que los promesantes que interpretan danzas reconocidas como "chilenas", las asumen como una "re-presentación" en el sentido artístico del término, ya que asumen como personajes a los más diversos grupos étnicos/nacionales/sociales: chinos, pieles rojas, cosacos, mexicanos, ancianos, toreros, etc. Mientras que, por otra parte, los promesantes que interpretan danzas consideradas como "bolivianas" estarían asumiendo una "representación" de lo boliviano en el sentido político del término, lo que tiene importantes consecuencias

\footnotetext{
${ }^{4}$ Entrevista a Carlos. (Calama, 11/11/08).

${ }^{5}$ Entrevista a Luis. (Calama, 28/10/08).
} 


\section{perifèria}

Número 15, diciembre 2011

www.periferia.name

dentro de la configuración de las identidades nacionales de los propios promesantes, tanto a nivel de referencia regional como nacional.

Los promesantes que desarrollan un alto grado de conciencia sobre su "bolivianidad", también parecen tener muy claras las consecuencias políticas formales implicadas en esta "representación" de lo boliviano. Tanto Luis como Carlos, ambos fundadores del Baile Tinkus, me manifestaron que comparten totalmente las críticas que desde Bolivia se establecen sobre el hecho de que en Chile se interpreten danzas que proceden del folklore boliviano. Es por ello que, cuando fundaron el Baile Tinkus presentaron una solicitud formal al Consulado de Bolivia en Calama para autorizar la fundación del Baile. En dicha solicitud sostenían que se encargarían de educar a la población chilena respecto a la procedencia de la danza, así como también se encargarían de guardar una completa fidelidad en términos de vestuario.

Un aspecto interesante que surge a partir de esta delimitación entre lo "boliviano" y lo "chileno" es observar cómo, a través de estas categoría, también se van construyendo ciertos parámetros de identidad vinculados con sentimientos de pertenencia local, ya sea a la ciudad de Calama y el ex-campamento minero de Chuquicamata, así como también en general a la zona norte de Chile. Carlos es muy enfático en señalar que esta mayor fidelidad de los Bailes Religiosos "bolivianos" al propio folklore de Bolivia es un elemento distintivo de la ciudad de Calama. Con orgullo me dice que: "Calama es representativo de Bolivia, solamente Calama. Ni Arica que está más cerca [de Bolivia], Calama solamente" ${ }^{\prime 6}$. El mismo Carlos establece una especie de frontera simbólica a partir de un mayor o menor grado de "bolivianidad" en el norte de Chile, estableciendo que "de Antofagasta pa' allá [al sur] viene siendo como chilenizado todo"7.

Es realmente llamativa esta forma de construcción de la identidad calameña o nortina, ya que aún cuando los promesantes se consideran totalmente chilenos, también es cierto que los grados de esa "chilenidad" son altamente variables en

\footnotetext{
${ }^{6}$ Entrevista a Carlos. (Calama, 11/11/08).

7 Ídem.
} 


\section{perifèria}

Número 15, diciembre 2011

www.periferia.name

relación con el nivel de vinculación afectiva que cada uno de ellos establece con la idea de la cultura boliviana. Se podría plantear, a modo de sugerencia interpretativa, una especie de escala cromática donde podríamos ir conjugando los diversos factores de vinculación cultural a la ciudad, a la zona norte de Chile y a los países de Bolivia y Chile, para así ir visualizando las formas de construcción identitaria desarrolladas por los promesantes de los Bailes Religiosos de Calama.

\section{Consideraciones finales}

A través de este breve recorrido por la propuesta teórica y los primeros resultados obtenidos de este proceso de investigación, he intentado mostrar parte de la relación que creo percibir entre ciertas expresiones folklórico-religiosas y las formas de construcción identitaria desarrolladas por los grupos sociales asentados en la zona minera de Calama, enfocándome específicamente en los promesantes de los Bailes Religiosos.

De modo general, se puede establecer la pertinencia relativa de la hipótesis planteada respecto a que los Bailes Religiosos, por medio de la práctica ritual y la expresividad coreográfica, han llegado a constituirse en mecanismos de configuración histórica de las identidades colectivas de clase y nación, a través de los cuales los promesantes establecen sus propios anclajes de "alteridad" o "diferencia". Sin embargo, y como he venido destacando, este sentido de alteridad se vería modificado en ocasiones, particularmente cuando los promesantes pasan a adoptar determinadas danzas como vehículos de expresión de su propia identidad. Este fenómeno nos sitúa en un ámbito donde estarían operando complejos mecanismos semióticos, a partir de los cuales se definirían los sentidos políticos de la representación.

Como forma de concretar esta propuesta de análisis, el trabajo de investigación se ha debido sustentar en dos ejes: una perspectiva histórica y otra etnográfica. Con respecto a la primera, se ha podido indagar en el contexto histórico de surgimiento de los Bailes Religiosos de la ciudad de Calama, percibiendo el hecho fundamental de que, en su gran mayoría, las primeras organizaciones procedían más bien del 


\section{perifèria}

Número 15, diciembre 2011

www.periferia.name

vecino campamento minero de Chuquicamata. De esta forma, se pudo establecer una propuesta de periodización sobre el proceso de surgimiento y difusión de los Bailes Religiosos en la zona: una primera etapa de "re-fundación" de la fiesta de Ayquina y el surgimiento de los primeros Bailes Religiosos entre los años treinta y sesenta del siglo XX; y una segunda etapa de mayor expansión marcada por la influencia "andina" en la creación de nuevos Bailes Religiosos, la que se iniciaría en la década de los años sesenta y que continuaría prácticamente hasta la actualidad.

Con respecto a la perspectiva etnográfica, se ha podido establecer la relevancia que todavía tiene la participación de los promesantes en los Bailes Religiosos para la conformación de sus identidades de clase. Esto se puede percibir en las propias dinámicas de tensión que se desarrollan al interior de los Bailes Religiosos. Pero sin embargo, pareciera ser que lo fundamental radicaría en una diferenciación entre Bailes "chicos y grandes". A través de ella, se estarían estructurando dos fuentes de sentido sobre las identidades de los promesantes: el "lujo" y la "humildad". Este asunto del creciente lujo que han asumido algunos promesantes, creo que puede ser considerado como un elemento novedoso en la construcción de las identidades de clase y las percepciones sociales sobre el prestigio dentro del mundo social calameño; asunto que, como ya he mencionado, tendría muchas analogías con el caso de las Fraternidades Folklóricas en Bolivia.

Por otra parte, se ha podido identificar también la relevancia que tiene la experiencia de los promesantes de los Bailes Religiosos en la construcción de las identidades nacionales. En este caso, estaría operando una distinción entre Bailes "chilenos y bolivianos". En el caso de los promesantes de los Bailes "bolivianos", se ha podido percibir una alto grado de conciencia respecto a la procedencia de la danza que interpretan y una mayor vinculación explícita con lo "re-presentado" (en términos artísticos), al límite de constituirse en una "representación" o "autorepresentación" de lo que se entiende como una identidad dividida entre la nacionalidad chilena formal y una latente identidad cultural boliviana.

De esta forma, tanto las indagaciones históricas como etnográficas nos indican la pertinencia de la perspectiva de análisis elaborada de manera específica para abordar el fenómeno de los Bailes Religiosos. Sin embargo, quedan todavía una 


\section{perifèria}

Número 15, diciembre 2011

www.periferia.name

serie de elementos por incorporar en la investigación, como son por ejemplo la relevancia que también tienen las categorizaciones identitarias de género, sobre todo tratándose en este caso de un contexto sociocultural minero considerado usualmente como "hiper-masculinizado".

Para finalizar, se podría establecer en términos generales que esta investigación nos invita a pensar en la existencia de una evidente relación entre los procesos de cambio e incorporación de determinadas danzas a las festividades patronales de la zona y los desarrollos socioeconómicos a nivel más general. Esto no quiere decir, en ningún caso, que piense en la existencia de una determinación de la "base" económica sobre la "superestructura" ideológica, sino que más bien pienso que se debería hacer hincapié en la conexión y mutua influencia que existe entre las representaciones culturales y las estructuras socioeconómicas. El mismo proceso de masificación de los Bailes Religiosos entre los sectores mineros del norte de Chile así lo siguiere y, en este mismo sentido, es todavía una tarea pendiente - a la vez histórica y etnográfica - rastrear esta compleja y dinámica relación entre las representaciones socioculturales y las diversas etapas de desarrollo del capitalismo minero en el norte de Chile.

\section{Bibliografía}

Abercrombie, Thomas (1992). "La fiesta del carnaval postcolonial en Oruro. Clase, etnicidad y nacionalismo en la danza folklórica". Revista Andina no 10 (2), pp. 279352.

(2003). "Mothers and mistresses of the urban bolivian public sphere: Postcolonial predicament and national imaginary in Oruro's Carnival", in Thurner, M. and Guerrero, A. (eds). After Spanish Rule: Postcolonial predicaments of the Americas. Durham and London: Duke University Press, pp. 176-220.

(2006). Caminos de la memoria y del poder. Etnografía e historia en una comunidad andina. La Paz: IFEA, Instituto de Estudio Bolivianos, Cooperación ASDI-SAREC. 


\section{perifèria}

Número 15, diciembre 2011

www.periferia.name

Absi, Pascale (2005). Los ministros del diablo. El trabajo y sus representaciones en las minas de Potosí. La Paz: PIEB, IRD, IFEA, Embajada de Francia en Bolivia.

Althusser, Louis (2003 [1975]). "Ideología y aparatos hegemónicos del Estado", en Žižek, S. (comp.). Ideología. Un mapa de la cuestión. Buenos Aires: Fondo de Cultura Económica, pp. 115-155.

Barragán, Rossana y Cárdenas, Cleverth, coords. (2009). Fiesta popular paceña. Tomo 3.- Gran Poder: La Morenada. La Paz: IEB; Convenio UMSA-ASDI/SAREC.

Barros, Alonso (2008). "Identidades y propiedades: Transiciones territoriales en el siglo XIX atacameño". Estudios Atacameños, Arqueología y Antropología Surandinas, 35, pp. 119-139.

Cardoso, Fernando y Faletto, Enzo (1971 [1969]). Dependencia y desarrollo en América Latina. Ensayo de interpretación sociológica. México D.F.: Siglo XXI.

Castro, Victoria y Martínez, José Luis (1996). "Poblaciones indígenas de Atacama". En Hidalgo, J., et al. Etnografía. Sociedades indígenas contemporáneas y su ideología. Santiago de Chile: Editorial Andrés Bello, pp. 69-109.

De Martino, Ernesto (2008). El folklore progresivo y otros ensayos. Edición a cargo de Carles Feixa. Barcelona: Museu d'Art Contemporani de Barcelona, Universitat Autònoma de Barcelona.

González, Sergio (2006). "La presencia indígena en el enclave salitrero de Tarapacá: Una reflexión en torno a la fiesta de La Tirana". Chungará, Revista de Antropología Chilena, 38 (1), pp. 35-49.

Gramsci, Antonio (2004 [1935]). "Observaciones sobre el folklore", en Gramsci, A. Antología. Selección, traducción y notas de Manuel Sacristán. Buenos Aires: Siglo XXI, pp. 488-491.

Hall, Stuart (1996). Who Needs 'Identity'?, in Hall, S. and Du Gay, P. (eds). Questions of Cultural Identity. London: SAGE, pp. 1-17.

Hobsbawm, Eric (2002 [1983]). "Introducción: La invención de la tradición". En Hobsbawm, E. y Terence, R. (eds). La invención de la tradición. Barcelona: Crítica, 


\section{perifèria}

Número 15, diciembre 2011

www.periferia.name

pp. 7-21.

Laan, Erik (1993). "Bailar para sanar. Estudio de la praxis de la peregrinación de los bailes religiosos del norte de Chile". Cuaderno de Investigación Social, 34, 89 págs. Martínez, José Luis (1985). "La formación del actual pueblo de Toconce. Siglo XIX". Chungará, 15, pp. 99-124.

Mercado, Javier (2005). "Combinación Mancomunal de Obreros de Antofagasta y politización popular, 1903-1906". [En línea]. Anuario de Pregrado 2004, no 1. $<w w w$.anuariopregrado.uchile.cl/articulos/Historia/Anuario_Pregrado_Combinacio_ Mancomunal.pdf>. [Consulta, 26 de septiembre de 2011].

(2009). "¿Antofagasta dormida? El movimiento social antofagastino frente a la huelga grande de Tarapacá. Diciembre de 1907". En Artaza, P., et al. A cien años de la masacre de Santa María de Iquique. Santiago de Chile: LOM, pp. 241-252.

(2010). "Organizaciones obreras, conciencia de clase y politización popular en Antofagasta". En Llagostera, A., et al. Región de Antofagasta. Pasado, presente y futuro en el Bicentenario de Chile 1810-2010. Antofagasta: Universidad Católica del Norte, Gobierno Regional de Antofagasta, pp. 171-185.

(2011). "Pintando danzas, creando nación: las danzas folclóricas y el dilema postcolonial en Bolivia". En Pensar Iberoamérica: Historia, memoria y nuevas tramas regionales. Valladolid: Servicio de Publicaciones, Universidad de Valladolid. (En prensa).

Nash, June (1979). We Eat the Mines and the Mines Eat Us: Dependency and Exploitation in Bolivian Tin Mines. New York: Columbia University Press.

Núñez, Lautaro (2004). La Tirana del Tamarugal. Santiago de Chile: Ediciones Universitarias, Universidad Católica del Norte.

Platt, Tristan (1983). "Conciencia andina y conciencia proletaria. Qhuyaruna y ayllu en el norte de Potosí". HISLA. Revista Latinoamericana de Historia Económica y Social, 2, pp. 47-73.

Salazar-Soler, Carmen (1987). "El Tayta Muki y la Ukupachu. Prácticas y creencias 


\section{revista de recerca i formació en antropologia}

\section{perifèria}

Número 15, diciembre 2011

www.periferia.name

religiosas de los mineros de Julcani, Huancavelica, Perú". Journal de la Société des Américanistes, 73, pp. 193-217.

(2002). Anthropologie des mineurs des Andes. Dans les entrailles de la terre. Paris: L'Harmattan.

Spivak, Gayatri (2009 [1993]). ¿Pueden hablar los subalternos?. Traducción y edición crítica de Manuel Asensi Pérez. Barcelona: Museu d'Art Contemporani de Barcelona.

Taussig, Michael (2010 [1980]). The Devil and Commodity Fetishism in South America. Chapel Hill: The University of North Carolina Press.

Thompson Edward (1963). The Making of the English Working Class. London: Penguin Books.

Thompson, Edward (2000 [1976]). "Historia y antropología". En Thompson, E. P. (2000 [1994]). Agenda para una historia radical. Barcelona: Crítica, pp. 15-43.

Van Kessel, Juan (1992). Cuando arde el tiempo sagrado. La Paz: Hisbol.

Weber, Max (1970 [1948]). From Max Weber: Essays in Sociology. Translated, Edited and with an Introduction by $\mathrm{H}$. H. Gerth and C. Wright Mills. London: Routledge \& Kegan Paul. 